\title{
Research on the Curriculum Design of Cloud Computing Technology and Application Specialty
}

\author{
Haiyan Liu ${ }^{1, a}$, Xiaomin Liu ${ }^{2^{\star}, \mathrm{b}}$ Yue Yang ${ }^{1, \mathrm{c}}$ and Guo Li $\mathrm{i}^{1, \mathrm{~d}}$ \\ ${ }^{1}$ Computer and Communication School, Beijing Information Technology College \\ Beijing, China \\ ${ }^{2}$ Water Conservancy and Civil Engineering College of Inner Mongolia Agricultural University, Inner \\ Mongolia \\ Inner Mongolia, China \\ ${ }^{3}$ Party Committee Office of East District, Beijing Information Technology College \\ Beijing, China
}

alhy_lj@sina.com, 'b13204717007@163.com, c48282192@qq.com, d guoli@bitc.edu.cn

\begin{abstract}
Keywords: Cloud Computing, Curriculum Design, Key Courses, Safeguard Measures
Abstract. Cloud computing and application specialty are carried out in the high vocation colleges and it is of great significance to study the professional curriculum. Firstly, this paper summarizes the development of cloud computing technology, analyzes the jobs of cloud computing technology. Secondly, the paper gives the courses system which is mainly composed of the general platform courses, specialty's supporting courses, specialty's key courses and specialty's development optional courses according to the job demands. Lastly, in order to ensure the smooth development of cloud computing technology and application specialty, safeguard measures are given.
\end{abstract}

\section{Introduction}

The data in the "the report of status and development trend 2014-2015 China cloud computing market” shows the market scale of China's cloud computing market was 38.36 billion yuan in 2014 . CCW Research shows that $67.5 \%$ of users have accepted cloud service patterns and started to use cloud computing services, or have achieved cloud platform within the enterprise. At the same time, with the Implementation of cloud computing "13th five-year" planning and the technological maturity of cloud computing and cloud storage, more and more enterprises will build the information technology system in the cloud. The cloud computing technology has become one of the important trends of development of science and technology in the next 10 years. The talent requirement of business in cloud computing will be greatly increased[1-3].

The structure of talents that cloud computing industry needs mainly presents the "pyramid" according to the types of talents needed[4-5]. The monitoring results show that the structure of talents is mainly distributed in the middle and lower reaches of the industrial chain. On the one hand, the talents whose jobs are the software development, software design and software analysis are located in the middle reaches of chain and their quantity makes up approximately $20 \% \sim 30 \%$ of total quantity. On the other hand, the skill-oriented and application-oriented talents are located in the lower reaches of chain and their quantity makes up approximately $60 \% \sim 70 \%$ of total quantity. The Figure 1 also shows the structure of cloud computing industry. The figure 1 shows that the talents that the infrastructure layer and running support layer need are more than the talents that the platform and software layer and application service layer need. However, the supply of cloud computing talent focuses on the upper reaches of the industrial chain, the supply is relatively weak in the middle and lower reaches of the industrial chain. 


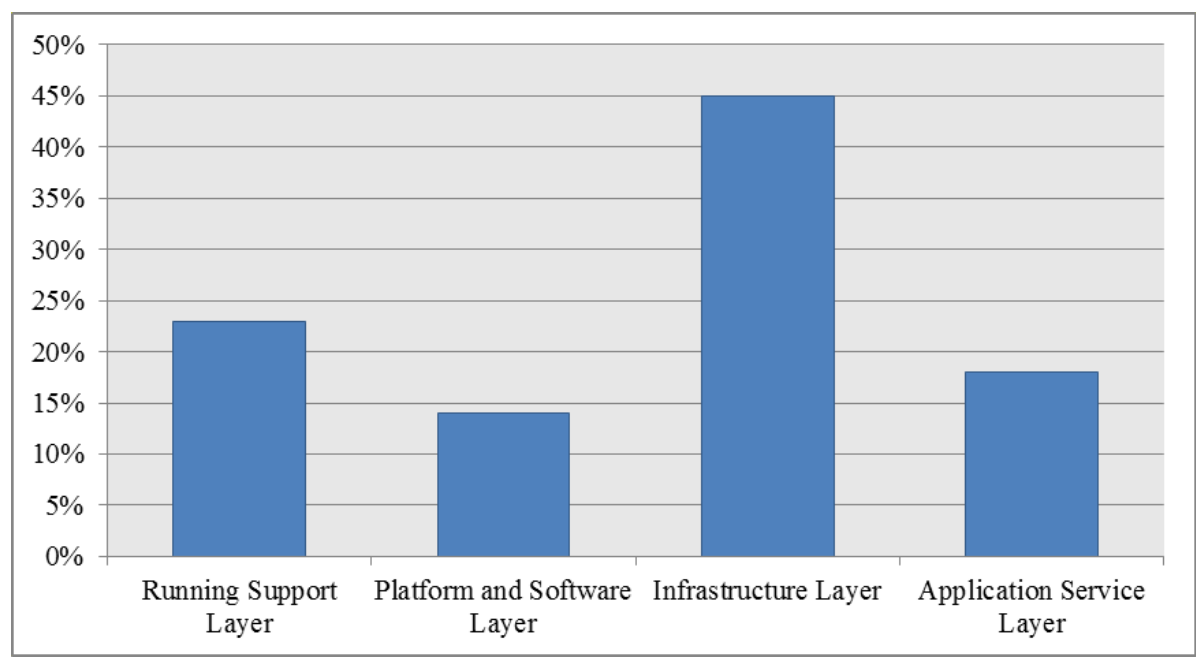

Figure 1. cloud computing industry structure in 2015, China

\section{Position analysis of Cloud Computing Technology and Application Specialty}

The cloud computing talent standard is divided into six levels: planning and design in cloud computing, project implementation in cloud computing, cloud operation and maintenance, development of cloud platform, cloud quality management, cloud operation and management in "Construction Guides of Comprehensive Standardization System of Cloud Computing” published by Ministry of Industry and Information Technology of the People's Republic of China. Social needs is large in cloud Project design in cloud computing, project implementation in cloud computing, system maintenance in cloud computing and development of cloud platform. These positions require the students to master the following skills:

The job of project design in cloud computing participates in the overall planning and design of cloud computing projects, decides the development of data and business disaster recovery program and provides the necessary technology and product selection strategy according to the development of the enterprises.

The project implementation in cloud computing is mainly responsible for deploying cloud platform system by using the cloud computing technology to achieve effective management of cloud computing resources. The main responsibilities include project implementation, training, project acceptance.

System maintenance in cloud computing is mainly responsible for the maintenance of the cloud platform, troubleshooting, analyzing the fault causes, improving the monitor of system, participating in the design and implementation of business systems and design and planning of the maintainability of the system architecture to ensure the operation of the system, to enhance the performance and stability of the cloud system and to implement cloud-related business.

Development of cloud platform is mainly responsible for overall design, development, maintenance optimization of projects. The job needs the rich experience of software design and application, the experience of virtualization algorithm implementation, the experience of resource management and can analyze and evaluate the overall structure of the system, optimize the system structure, select the appropriate practice reference models and construct the applicable cloud platform software architecture.

\section{Curriculum Design of Cloud Computing Technology and Application Specialty}

The course system is composed of the general platform courses, specialty's supporting courses, specialty's key courses and specialty's development optional courses. The courses relationship is shown figure 2. 


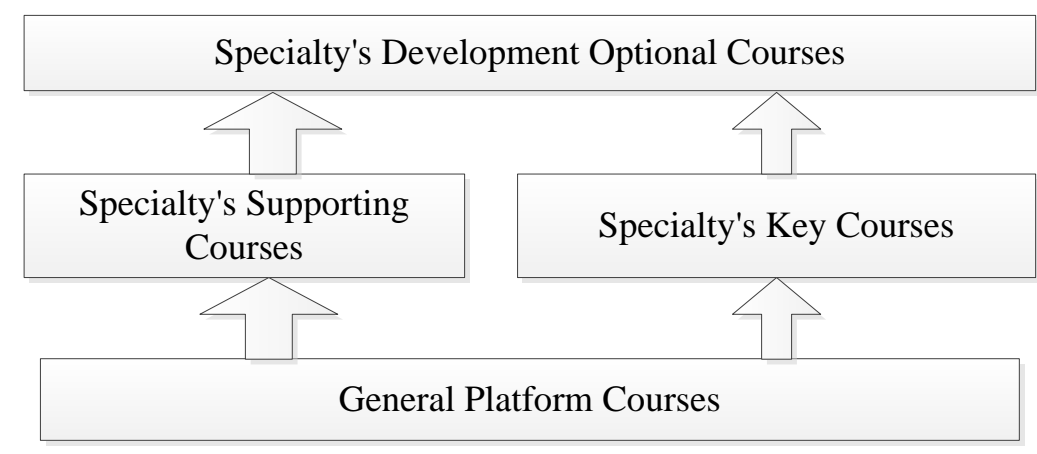

Figure 2. Courses relationship

General platform courses include applied mathematics, action-oriented learning and training, public English, sports, ideological and moral cultivation and legal basis, Mao Zedong Thought and the theory of socialism with Chinese characteristics, computer information processing technology, professional communication.

Specialty's key courses include configuration and security of Linux operating system, cloud computing infrastructure platform and applications, network interconnect technology, planning and deployment of cloud storage, deployment and operation of large data system, construction and operation of cloud data center, virtualization technology.

Specialty's supporting courses include computer network infrastructure, JAVA programming, database deployment, Andriod application development, information security infrastructure and advanced routing technology applications. These courses are mainly based on the key courses.

Specialty's development optional courses include data backup and disaster recovery, project management and project cost, networking technology and application, network security product configuration and management and network attack prevention and protocol analysis. These courses are elective courses, the main purpose is to expand and enhance the students' professional knowledge.

\section{Safeguard Measures of cloud computing technology and application specialty construction}

To ensure the smooth development of cloud computing technology and application specialty, the training mode, teaching staff and practice and training should be ensured, as show Figure 3 .

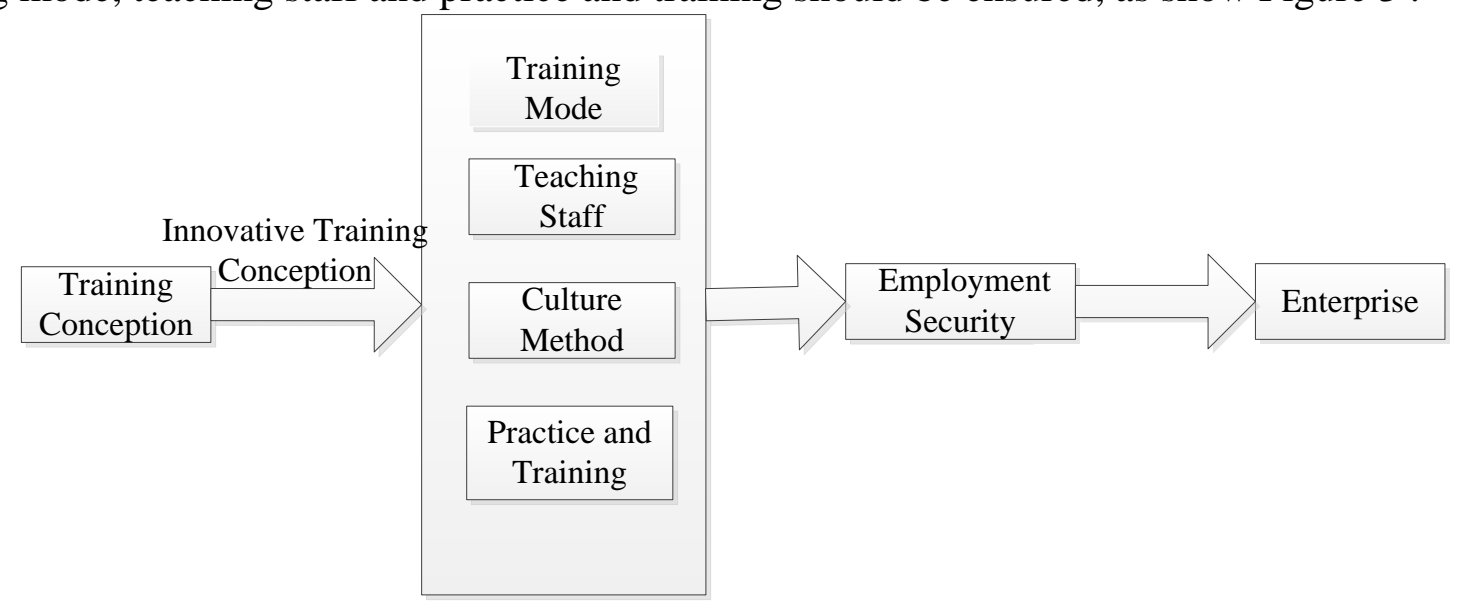

Figure 3. Safeguard measures of curriculum design

The teaching staff need be trained to enhance the professional skills of teachers and to improve the teaching level. At the same time, some enterprise teachers are invited to teach and to increase the actual experience of students.

The cloud computing is a comprehensive technology which involves in operation system, Internet planning management, virtualization technology, database technology and server technology. The students not only learn the theoretical knowledge of cloud computing but also master the basic technology of cloud computing in practice. Therefore, the practice and training is very necessary. 
Practice and Training mainly includes text entry training, production practice, obtaining certification of cloud computing technology training, productive training, working practice, graduation project.

\section{Summary}

The new IT resource sharing and application model brought about by cloud computing is another change. It is a certain guiding significance to combine with requirements of the post to set the professional curriculum system of cloud computer technology and application specialty. The course system needs to be further refined and modified in practice.

\section{Acknowledgements}

This work is supported by grants from Beijing Municipal Education Commission 2015annual Beijing Colleges and Universities Education and Teaching Reform fund project (No. 2015-ms212).

\section{References}

[1] KeLin Zhao, Long Zhu. Recommendations of Cloud Computing Technology and Application Specialty Construction in Higher Vocational Colleges. Journal of Nanjing Institute of Industry Technology. Vol. 15 (2015), p. 79-81.

[2] YongXia Jin. Exploration and Practice of Experimental Teaching of Cloud Computing Technology and Application Course. Computer Education. (2017), p. 146-148.

[3] Chi Hua, XiaoYan Gu, Rong Zhang, XiangYu Li. Design and Establishment of Cloud Computing Technology and Professional Training base Under Background of "Internet +". Experimental Technology and Management. Vol. 33 (2016), p. 79-81.

[4] YongXiang Wang, YiJun Liu, XueLi He. Exploration and Construction of the Curriculum System for the Cloud Computing Technology and Application Specialty of Higher Vocational Education - Based on the Investigation on the National First Scheme of Higher Vocational Demonstration Colleges. Vocational and Technical Education. Vol. 8 (2017), p. 29-32.

[5] ZhiMing Xie, Teng Wang, JunJie Li, Hui Shi. Research on Courses Design of Cloud Computing and Big Data Based on CDIO. Computer Education. Vol. 1 (2017), p. 47-52. 